\title{
Gabapentin inhibits multiple steps in the amyloid beta toxicity cascade
}

Juliana González-Sanmiguel ${ }^{1}$, Carlos Felipe Burgos ${ }^{1}$, Denisse Bascuñán ${ }^{1}$, Eduardo Javier Fernández-Pérez ${ }^{1}$, Nicolás Riffo-Lepe ${ }^{1}$, Subramanian Boopathi ${ }^{2}$, Arturo FernándezPérez ${ }^{3}$, Catalina Bobadilla-Azócar ${ }^{1}$, Wendy González ${ }^{2,4}$, Maximiliano Figueroa ${ }^{5}$, and Luis G. Aguayo ${ }^{1 *}$.

\section{Supportive Information}

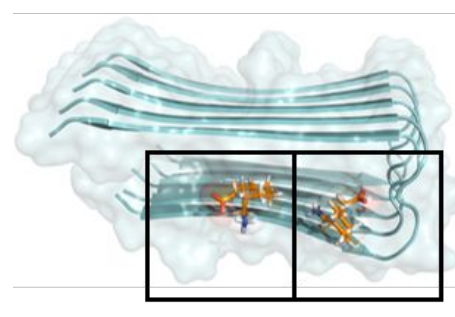

(2)

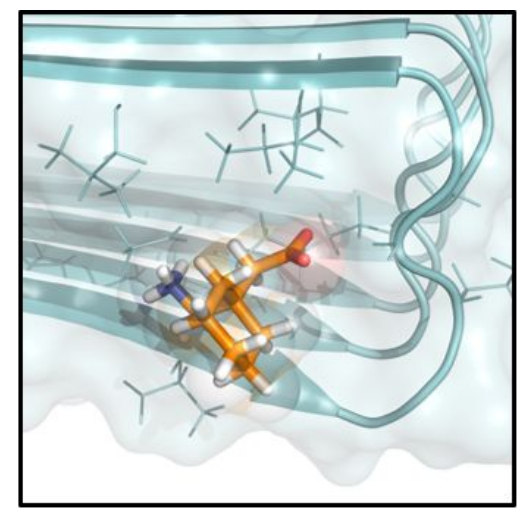

(1)

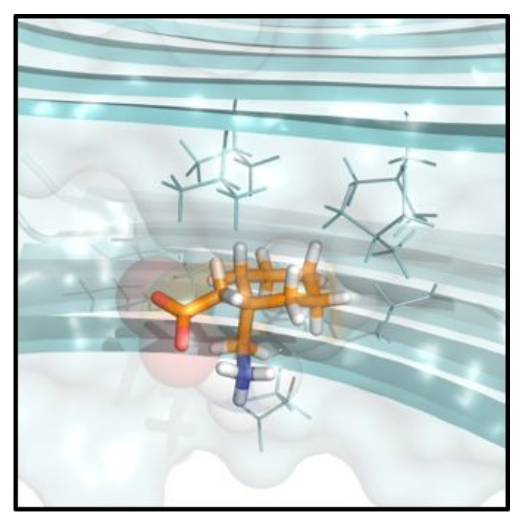

(2)

$$
\begin{array}{cc}
\text { DS } & -4.267 \\
\Delta \mathrm{G}_{\text {bind }} & -10.119 \mathrm{kcal} / \mathrm{mol}
\end{array}
$$

Figure S1. GBP interaction with the $\beta$-amyloid fiber. Protein-ligand docking generated from the structure of a $\beta$-amyloid peptide fiber (PDB: ID 2BEG) and GBP obtaining 2 potential binding sites in the regions involved with pore formation. Both interfaces have favorable docking score and $\Delta \mathrm{G}_{\text {bind }}$ values that support their potential interaction. 

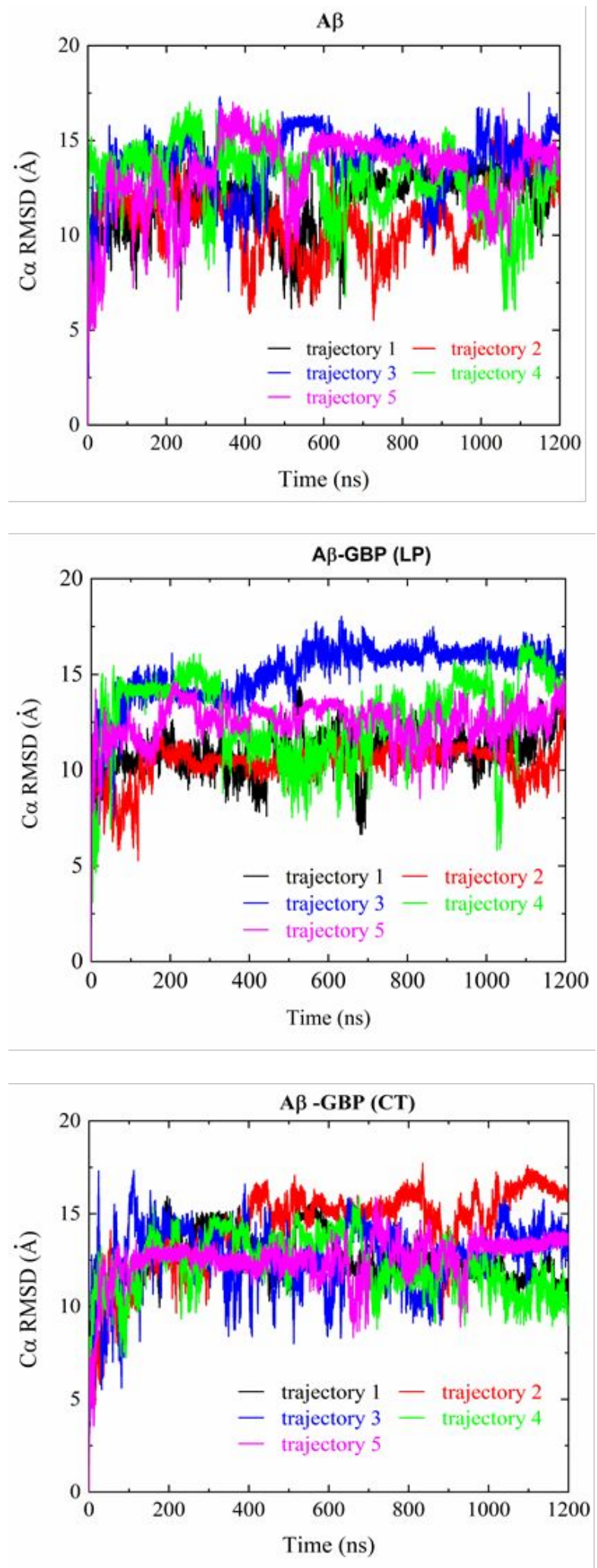

Figure S2. The C $\alpha$ Root Mean Square Deviation plotted over 1200 ns simulations for peptideligand configuration $A \beta, A \beta-G B P(L P)$ and $A \beta-G B P(C T)$. 